\title{
Reflection on Cultural Development Based on the Theory of Cultural Self-consciousness
}

\author{
Qianqian Ta0 ${ }^{1, ~ a ~}$, Haiwen Yan ${ }^{2, b}$ \\ ${ }^{1}$ School of Marxism, Wuhan University of Technology, Wuhan 430070, China; \\ ${ }^{2}$ Wuhan Changjiang Waterway Rescue and Salvage Bureau, Wuhan 430000, China \\ a165268803@qq.com, byan_hw@qq.com
}

Keywords: Global, Cultural self-consciousness, Cultural development, reflect, critique.

\begin{abstract}
Cultural self-consciousness" is a new proposition put forward by sociologist Fei Xiaotong. He advocated treating the foreign culture with a concept of harmony in diversity and mutual perfection. Reflection is the core of "cultural self-consciousness" reflected, the culture reflection on their cultural sources, gains and losses based on cultural self-confidence, insight into the advantages and disadvantages of their own culture on the basis of rational thinking. Economic globalization is the inevitable trend of the development of productive forces, in cross cultural communication, should be good at using the "others" perspective to understand the world, we should oppose "cultural separatism", but also against the "cultural hegemony". Arouse the cultural self-consciousness of the whole nation,to make the cultural self-consciousness rise to the rational level, will greatly promote the development of national culture.
\end{abstract}

\section{Introduction}

Under the background of globalization, the culture has been diversified,the national cultures of the world are closely related to each other,cultural exchanges and integration has reached an unprecedented depth and breadth,the cultures of all ethnic groups in the world show the trend of coexistence, conflict, infiltration and blending.The relationships between cultural globalization and diversification 、 between local culture and foreign culture 、 different regions and nations is placed in front of all mankind,people need to recognize the "other" culture,can't be lost in cross cultural communication,too much influenced by the culture and thought of "the other", will lead to the loss of self-identity. The awakening of a nation, first of all, is the awakening of culture,a culture only has the ability of self reflection and introspection to gain the strength of the forward.Multi cultural communication in the global context requires mutual respect, communication and coexistence of cultural self-consciousness,that is, " prettify itself 、prettify others 、prettify together、world harmony." Cultural concept of "harmony but not sameness 、 prettify together".

\section{The Epistemology of "Cultural Self-consciousness"}

The proposition of "cultural self-consciousness" was originally proposed by sociologist Fei Xiaotong in China. This proposition reflects the thoughts of people living in a certain culture on maintaining the tension between the national characteristics and multi-culture. He pointed out that the so-called "cultural self-consciousness" indicated that people who live in a certain culture should be self-aware on their own culture, understand its origin, formation process, characteristics and its development trend without any cultural regression and instauration. In the meantime, wholesale westernization or otherization is not advocated. Self-knowledge is to strengthen the independent ability of cultural transformation and obtain independent position to adapt to new environment, new era and new cultural selection[1]. "Cultural self-consciousness" can be understood as self awareness of culture, which is the conscious awareness of the cultural subject. The cultural subjects should have a full understanding on their own culture. Cultural self-consciousness is not an abstract word. It is the rational understanding and grasping of the destiny of mankind. Furthermore, cultural 
self-consciousness is a rational cultural cognitive state, and rational thinking and practice on cultural construction, cultural choice and cultural development on social development by cultural subjects.

\section{Essential Analysis of "Cultural Self-consciousness"}

The research on "Cultural self-consciousness" is a study on how the cultural subject fully understand the national culture, namely the cultural subject's awareness for self-knowing, introspection and self-transcendence of their own cultural, its essence involves multiple levels. In general, the essential analysis of culture consciousness has the following layers:

\subsection{Cultural Identity.}

Cultural identity is the culture of the subject to recognize their own culture,Only by recognition of their own unique culture, a nation has the meaning of existence in culture. The term "identity" is a professional term in the behavior science, which is a kind of subjective orientation of the subjective self. "Identity" is a kind of emotion which is called "belonging" and is a kind of sense of belonging[2].Cultural identity is more "traditional" cultural identity.Mr. Fei Xiaotong emphasizes the importance of "traditional" culture, he thought towards the culture must first understand its cultural origin, formation process and characteristics, only in the full understanding of their own culture, will produce cultural self-knowledge and self-confidence, will produce the thinking and reflection.The identity of the local culture appears in defending the subject status of the national culture, which is a reflection of consciousness of their own cultural subject. A country or a nation should have its own unique culture and can't put itself in a state of having rootless culture. Defending the native culture is to keep main consciousness of a nation. The identification of the diversified culture is to respect different cultures, respect cultural diversity and respect for the rationality of the existence of different cultures. In the context of globalization, cultural change and blend of various forms is an inevitable process. "Culture" emphasizes unique development path of different human groups. People live in different environment and different languages is formed, which results in different cultures. Compared to the theory of "civilization conflict", cultural self-consciousness tend to the old saying that "gentleman gets along with others, but does not necessarily agree with them" [3].

\subsection{Cultural Comparison.}

Cultural comparison is a way of cultural self-consciousness. People often take their own culture for granted, and It's difficult to jump out to look upon themselves. Only by comparing with other cultures, they can find the differences and gaps between themselves and others. Cultural comparison can make a comparison with unlimited space between cultures of different groups and traditions and realize the cultural integration, and then achieve the purpose of identifying the similarities and differences of cultures As well as the reason of that[4]. Although it is true that a variety of cultures are different, but there are some of the same development models. Through comparing and analyzing the cultural traits of many "sample nationals" around the world , we Can find the cultural traits from simple to complex of different nations. Cultural communication is a process of understanding and recognition between each other. If we refuse cultural communication and cultural exchange, it will lead to the trend of "one-way cultural anthropology" more serious and deviate the conception of "two-way cultural anthropology". Only under comparison and reference between many other cultures, one culture can overcome self-centered illusion and identify its own uniqueness and relativity. If every culture confined to its own cultural circle and recognized and evaluated themselves only on their own framework and scale, it will be very easy to produce insurmountable limitations and blind spots, namely the so called verse that "the true face of Lushan is lost to my sight, for it is right in this mountain that I reside". The cultural self-consciousness needs the perspective transformation of "mutual subjectivity" and "mutual reference” [5].

\subsection{Cultural Reflection.}

Reflection is actually an attempt of cultural self-consciousness. The meaning of cultural self-consciousness actually includes the reflection on the civilization of oneself and others. Reflection on oneself often helps to understand the relationship between different 
civilizations[6].Reflective consciousness is the nuclear and essential expression of cultural self-consciousness. The essence of cultural self-consciousness is the conscious reflection on the source and the gain and loss of their own culture on the basis of cultural confidence. If we are lack of consciousness of cultural reflection and don't know the origin, e formation process and characteristics of our culture, we will not grasp ourselves accurately and easily been leaded to complacency on the development of our national culture, and then form extremely arrogant cultural centralism or self-preservation cultural tribalism. Therefore, consciously understanding the generating process of the national culture, grasping the characteristics of the national culture, regarding the cultural phenomenon which we place ourselves in and is rooted in the values, the way of thinking, aesthetic temperament and interest and behavior of the world we live in as the object of the rational thinking and conscious attention, revealing the spiritual kernel, putting insight into the advantages and disadvantages, all of these are the premise of the fundamental sense of cultural self-consciousness.

\subsection{Cultural Criticism.}

Cultural criticism refers to that the cultural subject checks and rationally reflects on the way of existence of their own culture and evolution process. Criticism is not that cultural subject express its resentment and anger to the popular culture or just simply criticizes and reprimands to the cultural phenomenon[7]. The intellectual elite reveals and holds the anomie of the dominant cultural crisis by rational reflection and the cultural subject uses its theory expression to analyze the pros and cons of the popular culture, which is a kind of more profound and rational thinking. During deconstruction of the Cultural Criticism, its deeper purpose is actually moving towards construction. Cultural self-consciousness is the premise and foundation of cultural criticism. Only on the basis of fully understanding of their own culture, the cultural criticism will not be blind and arbitrary. The motto "know yourself" on the Delphy temple opens the enlightening road to human's self-understanding and self-criticism. Through the criticism of culture, people have reached criticism and understanding of their own, which is the way to achieve cultural self-consciousness.

\subsection{Cultural Innovation.}

Innovation is a interrupt of variable, then a qualitative change will be produced, which is a kind of leap and sublation. Cultural innovation is the deconstruction to the original value system and the fixed mode of thinking of the mind, So as to construct new ideas, knowledge and system. To a large extent, cultural difference is the difference of cultural value. Cultural value is the evaluation standard and ideal orientation of a nation's idea, behavior, communication and so on. The value system of any culture contains morality, science, politics, law, literature, art and religious aspects or elements. But because the connection way, function mode and structural order of each value field are different, thus the overall cultural characteristics and functions of different value systems are formed[8]. When the multiple cultures blend, cultural innovation should be proper meaning of cultural self-consciousness. Cultural innovation is the extension of cultural self-consciousness. In the cultural construction, refusing to change, following the beaten track, lacking of methods and strategies are not really cultural self-consciousness. Cultural self-consciousness, as a kind of rational cultural reflection, reflects the past and present of culture. After analyzing the advantages and disadvantages of our own culture, we should be able to grasp the future development trend of our own culture. Cultural self-consciousness should be creative and pioneering.

\section{The Process Analysis of "Cultural Self-consciousness"}

Cultural self-consciousness is a kind of activity which has explicit external orientation,People has a point of depth in the transformation of the old culture.The depth of the reflection and reconstruction of the old culture represents the degree of the cultural self-consciousness.Cultural self-consciousness has experienced identity, comparison, reflection, criticism and innovation,this is a logical process from the shallower to the deeper,it passes through the surface layer, middle layer and then to the deep"conscious" process. The cultural main body first is to carry on the consciousness to the surface of cultural psychology, it only touches the cultural level and the cultural psychology level.The surface of cultural structure is the cultural and psychological morals 
aspects, it refers to the social political habits、moral habits 、 lifestyle 、 customs and so on , it is on the surface of the social life of the psychological performance[9]. The cultural main body will be aware of this phenomenon, begin to analyze and criticize the surface layer of the cultural psychology,because of the decline of an old culture,all the drawbacks are first revealed in the cultural psychology of morals .

Through the attention of the surface and the "consciousness" to enter the middle reflection of the cultural structure, The middle level of the cultural structure mainly refers to the cultural system and cultural mentality.The cultural critic always tries to criticize the old culture in the minds of the people who are exposed in the old culture.The cultural main body criticizes the old culture idea,this is the reflection of cultural psychology to a deeper level of consciousness, and finally into the deep cultural self-consciousness.The deep cultural self-consciousness touches the deep structure of cultural psychology, namely, the cultural spirit,reflection on this level should rise to the philosophical and psychological analysis,this can clearly determine the cultural values and thinking of cultural main body.From the perspective of history of thought,the emergence of cultural philosophy in twentieth Century to make cultural self-consciousness in the period highlights. Various cultural phenomena appeared in twentieth Century,philosophy begins to focus on culture,Research on the formation, development and change of culture, the essence of culture,As well as the interactive process of variety of specific forms of culture , to construct a system of philosophical theory.Cultural self-consciousness is the product of modernization,with the gradual formation of modern reflection,people gradually see the influence of the culture of the historical operation mechanism and the schema,the consciousness and reflection of culture is more and more deeply.

\section{Conclusion}

The spiritual products of various nationalities have become public property.The one-sided and limited nature of the nation becomes more and more impossible, so it is a kind of literature of the world, which is formed by many kinds of national and local literature."Here the literature refers to science, philosophy and politics etc. In fact, the physical contact with the spirit of communication, material exchanges itself will have a common cultural spirit.Economic globalization is the inexorable trend of the development of productive forces, to make the direction of globalization is to promote human civilization, benefit most countries, Should follow certain value principle, should reflect a certain cultural spirit.The spirit of science and technology should be integrated with humanistic spirit, The spirit of science and technology is the product of modern western industrial revolution[10]. It mainly emphasizes the instrumental nature of science and technology,in the past, the development of productive forces more attention to the spirit of science and technology, but technology has its negative effect,some of today's global problems can be solved by science and technology, but there must also be a common humane care in order to effectively solve the global problem.The unification of scientific spirit and humanistic spirit is also a basic trend of human cultural spirit in the era of globalization

At present, the coordination mechanism in the international community is still dominated by the west,human beings have entered a society with mutually beneficial cooperation and fair competition,in the era of globalization, all countries should adhere to the unity of the spirit of mutually beneficial cooperation and the spirit of fair competition, In itself, this is a contribution to the development of the international economy and society. What is the common theme of the world, different countries have different views, globalization does not mean that solve the contradictions of national economic and political interests, but the contradiction solution provides the opportunity and means, globalization needs peace and development have become the themes of the times.The theme of peace and development in the era of globalization should and will become the highest concern of human culture. 


\section{References}

[1] X.T.Fei, Fei xiaotong corpus. Beijing:Peking University,1995,pp197-220.

[2] R.Zhang,Cultural consciousness Theory. Huazhong University of Science and Technology,2010,pp45.

[3] T.J.Ma,The Cultural Nature of Philosophy and the Philosophical Nature of Culture.Seeking Truth.2009, vol.36,pp.16-20.

[4] X.T.Fei,"Prettify Together" and "Human Civilization",QunYan,2005,vol.2,pp.1.

[5] Z.H.Lu,Cultural globalization and Strategic choice of cultural development.Journal of Party School of the CPC Central Committee,2004,vol.4,pp.35-38.

[6] David Gentilcore ,The Culture of Cleanliness in Renaissance Italy.Bulletin of the History of Medicine,2008. vol. 82,pp. 708-710.

[7] David M. Rosenthal,The Nature of Consciousness.Mind Oxford.2004,vol3,pp.113-116.

[8] B.Q.Liu, Popular Cultural Criticismand Popular Cultural Innovation.The Northern Forum,2010, vol.3, pp.133-134.

[9] Z.G.Li,Cultural Self-consciousness and Cultural Development.Journal of Sun Yatsen University (Social Science Edition),2004, vol.44, pp.161-165.

[10]X.D.Liu.,S.Dan, Refleetion at the Cultural Intersection. Education Research,2005, vol.4,pp.38-43. 